\title{
Validation and refinement of prediction models to estimate exercise capacity in cancer survivors using the steep ramp test
}

\author{
Author(s) \\ Stuiver, Martijn M; Kampshoff, Caroline S; Persoon, Saskia; Groen, Wim; van Mechelen, \\ Willem; Chinapaw, Mai J M; Brug, Johannes; Nollet, Frans; Kersten, Marie-José; Schep, \\ Goof; Buffart, Laurien M
}

Publication date

2017

Document Version

Final published version

Published in

Archives of physical medicine and rehabilitation

Link to publication

Citation for published version (APA):

Stuiver, M. M., Kampshoff, C. S., Persoon, S., Groen, W., van

Mechelen, W., Chinapaw, M. J. M., Brug, J., Nollet, F., Kersten, M-J.,

Schep, G., \& Buffart, L. M. (2017). Validation and refinement of prediction models to estimate exercise capacity in cancer survivors using the steep ramp test. Archives of physical medicine and rehabilitation, 98(11), 2167-2173.

It is not permitted to download or to forward/distribute the text or part of it without the consent of the author(s) and/or copyright holder(s), other than for strictly personal, individual use, unless the work is under an open content license (like Creative Commons).

If you believe that digital publication of certain material infringes any of your rights or (privacy) interests,

please let the Library know, stating your reasons. In case of a legitimate complaint, the Library will make the material inaccessible and/or remove it from the website. Please contact the library:

https://www.amsterdamuas.com/library/contact/questions, or send a letter to: University Library (Library of the University of Amsterdam and Amsterdam University of Applied Sciences), Secretariat, Singel 425, 1012 WP Amsterdam, The Netherlands. You will be contacted as soon as possible. 


\title{
Validation and Refinement of Prediction Models to Estimate Exercise Capacity in Cancer Survivors Using the Steep Ramp Test
}

\author{
Martijn M. Stuiver, PhD, ${ }^{a, b, c}$ Caroline S. Kampshoff, MSc, ${ }^{d}$ Saskia Persoon, MSc, ${ }^{e}$ \\ Wim Groen, PhD, ${ }^{f}$ Willem van Mechelen, PhD, ${ }^{d}$ Mai J.M. Chinapaw, PhD, \\ Johannes Brug, PhD, ${ }^{\mathrm{g}}$ Frans Nollet, PhD, ${ }^{\mathrm{e}}$ Marie-José Kersten, PhD, ${ }^{\mathrm{h}}$ Goof Schep, PhD, ${ }^{\mathrm{i}}$ \\ Laurien M. Buffart, PhD ${ }^{j, k, l}$
}

From the ${ }^{a}$ Department of Physical Therapy, Netherlands Cancer Institute, Amsterdam, The Netherlands; ${ }^{b}$ Department of Clinical Epidemiology, Biostatistics and Bioinformatics, Academic Medical Center, University of Amsterdam, Amsterdam, The Netherlands; 'ACHIEVE, Faculty of Health, Amsterdam University of Applied Sciences, Amsterdam, The Netherlands; ${ }^{d}$ Department of Public \& Occupational Health/EMGO+ Institute, VU University Medical Center, Amsterdam, The Netherlands; ${ }^{e}$ Department of Rehabilitation, Academic Medical Center, University of Amsterdam, Amsterdam, The Netherlands; ${ }^{\prime}$ Division of Psychosocial Research and Epidemiology, Netherlands Cancer Institute, Amsterdam, The Netherlands; ${ }^{g}$ Faculty of Social and Behavioural Sciences, University of Amsterdam, Amsterdam, The Netherlands; ${ }^{h}$ Department of Hematology, Academic Medical Center, University of Amsterdam, Amsterdam, The Netherlands; ${ }^{i}$ SportMáx, Maxima Medical Center, Eindhoven, The Netherlands; ${ }^{j}$ Department of Epidemiology and Biostatistics/EMGO+ Institute and ${ }^{k}$ Department of Medical Oncology, VU University Medical Center, Amsterdam, The Netherlands; and 'Exercise Medicine Research Institute, Edith Cowan University, Joondalup, Australia.

\footnotetext{
Abstract

Objective: To further test the validity and clinical usefulness of the steep ramp test (SRT) in estimating exercise tolerance in cancer survivors by external validation and extension of previously published prediction models for peak oxygen consumption $\left(\mathrm{Vo}_{2 \text { peak }}\right)$ and peak power output $\left(\mathrm{W}_{\text {peak }}\right)$. Design: Cross-sectional study.

Setting: Multicenter.

Participants: Cancer survivors $(\mathrm{N}=283)$ in 2 randomized controlled exercise trials.

Interventions: Not applicable.

Main Outcome Measures: Prediction model accuracy was assessed by intraclass correlation coefficients (ICCs) and limits of agreement (LOA). Multiple linear regression was used for model extension. Clinical performance was judged by the percentage of accurate endurance exercise prescriptions. Results: ICCs of SRT-predicted $\mathrm{VO}_{2 \text { peak }}$ and $\mathrm{W}_{\text {peak }}$ with these values as obtained by the cardiopulmonary exercise test were .61 and .73 , respectively, using the previously published prediction models. $95 \%$ LOA were $\pm 705 \mathrm{~mL} / \mathrm{min}$ with a bias of $190 \mathrm{~mL} / \mathrm{min}$ for $\mathrm{Vo} 2$ peak and $\pm 59 \mathrm{~W}$ with a bias of $5 \mathrm{~W}$ for $\mathrm{W}_{\text {peak. }}$. Modest improvements were obtained by adding body weight and sex to the regression equation for the prediction of $\mathrm{Vo}_{2 \text { peak }}\left(\mathrm{ICC}, .73 ; 95 \% \mathrm{LOA}, \pm 608 \mathrm{~mL} / \mathrm{min}\right.$ ) and by adding age, height, and sex for the prediction of $\mathrm{W}_{\text {peak }}$ (ICC, .81; $95 \% \mathrm{LOA}, \pm 48 \mathrm{~W}$ ). Accuracy of endurance exercise prescription improved from $57 \%$ accurate prescriptions to $68 \%$ accurate prescriptions with the new prediction model for $\mathrm{W}_{\text {peak }}$.

Conclusions: Predictions of $\mathrm{VO}_{2 \text { peak }}$ and $\mathrm{W}_{\text {peak }}$ based on the SRT are adequate at the group level, but insufficiently accurate in individual patients. The multivariable prediction model for $\mathrm{W}_{\text {peak }}$ can be used cautiously (eg, supplemented with a Borg score) to aid endurance exercise prescription. Archives of Physical Medicine and Rehabilitation 2017;98:2167-73
}

(c) 2017 by the American Congress of Rehabilitation Medicine

The Resistance and Endurance exercise After Chemotherapy and EXercise Intervention after Stem cell Transplantation studies were supported by the Alpe d'HuZes/KWF Fund. The research grants were provided by the Dutch Cancer Society (grant nos. ALPE 2009-4619 and ALPE 2009-4620).

Disclosures: W.v.M. is a director-shareholder of a VU University Medical Center spin-off company Evalua Nederland BV and a nonexecutive board member of Arbo Unie BV. 
Many cancer survivors experience severe loss of exercise capacity. $^{1,2}$ This may interfere with performance of daily activities. ${ }^{3}$ Also, poor exercise tolerance is a risk factor for overall mortality. ${ }^{4-6}$ Exercise is recommended for cancer survivors, because it can improve physical fitness and health-related quality of life. ${ }^{7}$

For optimal exercise prescription for cancer survivors, cancer and cancer treatment-related side effects should be taken into account, as well as basic exercise principles such as specificity, progression, and overload. ${ }^{8,9}$ To evaluate current exercise capacity and to ensure adequate training progression and overload during exercise programs, repeated exercise capacity testing is required. ${ }^{9}$ One of the main indicators of individual exercise capacity is peak oxygen consumption $\left(\mathrm{V}_{\mathrm{O}_{2 \text { peak }}}\right)$.

The criterion standard of $\mathrm{Vo}_{2 \text { peak }}$ assessment is a maximal incremental exercise test with breath gas analysis and electrocardiography, usually referred to as cardiopulmonary exercise test (CPET). ${ }^{10}$ As the performance of CPET requires specific expertise and specialized equipment, the test is not readily available for exercise prescription in primary care or even in many hospital settings. $^{2}$ As a result, clinicians often turn to less resourcedemanding (often submaximal) exercise tests, among which is the steep ramp test (SRT).

The SRT is a short maximal cycle ergometer test that was developed to support interval training prescription for patients with heart failure, without the need for breath gas analysis. ${ }^{11}$ The test uses a fast increasing workload of $25 \mathrm{~W}$ every 10 seconds. The maximum workload achieved is referred to as the maximal short exercise capacity (MSEC). The largely anaerobic nature of the SRT makes it suitable for dosing interval training and monitoring response. ${ }^{11}$ In a sample of 37 cancer survivors, De Backer et al ${ }^{12}$ showed that the SRT has excellent test-retest reliability and a small SEM. The MSEC also has a strong correlation with $\mathrm{VO}_{2 \text { peak }}$ and peak power output $\left(\mathrm{W}_{\text {peak }}\right)$ as assessed by a regular CPET, ${ }^{12,13}$ and currently 2 linear regression equations to estimate $\mathrm{VO}_{2 \text { peak }}$ and $\mathrm{W}_{\text {peak }}$ from the MSEC in cancer survivors are available. ${ }^{12}$ The SRT seems to be a promising measure to estimate aerobic exercise capacity and to tailor exercise prescriptions, not only for short bouts of interval training but also for longer endurance training bouts, to the capacity of individual cancer survivors. However, the prediction models as presented by De Backer et $\mathrm{al}^{12}$ have not yet been externally validated in a different (and larger) sample of cancer survivors. Also, the predictions of $\mathrm{Vo}_{2 \text { peak }}$ and $\mathrm{W}_{\text {peak }}$ by these equations lack precision, with $95 \%$ prediction margins of $616 \mathrm{~mL} / \mathrm{min}$ and $63 \mathrm{~W}$ for $\mathrm{Vo}_{2 \text { peak }}$ and $\mathrm{W}_{\text {peak }}$, respectively. ${ }^{12}$ This hampers the use of the SRT for valid estimation of $\mathrm{VO}_{2 \text { peak }}$ or $\mathrm{W}_{\text {peak }}$ and for tailoring other types of aerobic exercises (eg, endurance training with continuous load) in individual patients, because prescribed intensities are often too high or too low. Hence, further improvement of the prediction models is required before the SRT can be considered as a substitute for the CPET.

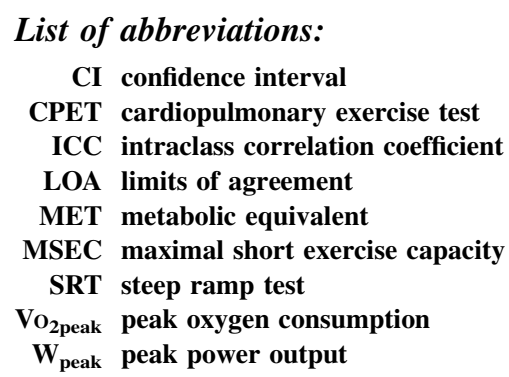

Better generalizability might be achieved by using a larger sample size to build the regression models. In addition, because age, sex, height, and weight are associated with maximal exercise capacity, ${ }^{14}$ we hypothesized that the accuracy of the prediction of $\mathrm{VO}_{2 \text { peak }}$ and $\mathrm{W}_{\text {peak }}$ based on the MSEC could be improved by including these variables in the regression equation.

Thus, the objectives of this study were to externally validate the previously published prediction models for $\mathrm{Vo}_{2 \text { peak }}$ and $\mathrm{W}_{\text {peak }}{ }^{12}$ in a larger sample of cancer survivors and to explore whether predictions of $\mathrm{VO}_{2 \text { peak }}$ and $\mathrm{W}_{\text {peak }}$ as well as exercise prescriptions could be improved by extending the regression model.

\section{Methods}

\section{Patients and measurements}

This study used data collected in 2 randomized controlled exercise trials-EXercise Intervention after Stem cell Transplantation study $^{15}$ and Resistance and Endurance exercise After Chemotherapy study ${ }^{16,17}$-in cancer survivors, which were part of the Alpe d'HuZes Cancer Rehabilitation program. ${ }^{18}$ The EXercise Intervention after Stem cell Transplantation study was a multicenter randomized controlled trial in which 109 patients, who were recently treated with autologous stem cell transplantation for multiple myeloma or (non-)Hodgkin lymphoma, were recruited from 9 hospitals. ${ }^{15}$ The Resistance and Endurance exercise After Chemotherapy study was a multicenter randomized controlled trial in which 277 patients diagnosed with breast, colon, ovarian, cervix, or testis cancer or lymphoma, who had recently completed primary cancer treatment (including chemotherapy), were recruited from 9 hospitals. ${ }^{16,17}$ Approval for these studies was obtained from medical ethics committees of all participating centers, and all participants provided written informed consent.

Both trials included a CPET at baseline and follow-up assessments and used an SRT to support exercise prescription and adaptation. The present analysis uses the first SRT results of each patient, as obtained shortly after the baseline CPET. For the EXercise Intervention after Stem cell Transplantation study, this concerned patients in the intervention group only $(n=54)$. Time between baseline CPET and SRT in all eligible patients ranged between 0 and 41 days. For the purposes of the present study, we only included available data from patients in whom the SRT and CPET were performed within 30 days and who had not yet started exercise training. Consequently, combined tests were available for 283 patients $(85 \%)$ with a median interval of 8 days (interquartile range, 6-10d).

\section{Exercise tests}

Patients performed both tests on an electronically braked cycle ergometer using standardized protocols. Details of the testing procedures are described elsewhere. ${ }^{15,16}$ In short, the CPET used a ramp protocol with gradually increasing workload that was adjusted to each patient with the aim to achieve the maximum performance within 8 to 12 minutes. Patients were instructed to cycle with a pedal frequency between 60 and 80rpm and were encouraged to continue cycling until exhaustion or inability to maintain the prescribed pedal frequency. During the test, heart rate was monitored continuously using a 12-lead electrocardiogram 
and expired gases were collected breath by breath using gas analysis for $\mathrm{O}_{2}, \mathrm{CO}_{2}$, and respiration volume. $\mathrm{VO}_{2 \text { peak }}$ (in milliliters per minute) was determined as the average oxygen uptake during the 15-second interval in which maximum oxygen uptake was attained. $\mathrm{W}_{\text {peak }}$ (in watts) was determined as the highest workload reached during the test.

The SRT started after a 4-minute warming-up process at $10 \mathrm{~W}$. During the test, the workload increased by $25 \mathrm{~W}$ every 10 seconds, starting at $25 \mathrm{~W}$. The test ended when the cycling pedal frequency fell below 60rpm. The MSEC was calculated as the workload of the last completed stage plus $2.5 \mathrm{~W}$ for each second in the current stage. ${ }^{12}$

\section{Statistical analysis}

Descriptive statistics for the sample were calculated using mean and SD, median and interquartile range, or frequency and percentage, as appropriate, on the basis of data type and distribution.

\section{External validation and calibration-in-the-large}

We first evaluated the external validity of the prediction models as derived by De Backer et $\mathrm{al}^{12}$ by examining the accuracy of the predictions in the entire sample. Intraclass correlation coefficients (ICCs; 2-way random, absolute agreement, single measure) were calculated between the predicted values (denoted $\mathrm{VO}_{2 \text { peak }}^{\text {pred }}$ and $\mathrm{W}_{\text {peak }}^{\text {pred }}$ ) and values measured during the CPET (denoted $\mathrm{VO}_{2 \text { peak }}^{\text {cpet }}$ and $\mathrm{W}_{\text {peak }}^{\text {cpet }}$ ). Second, we updated the intercept of the regression equation to reflect the lower mean $\mathrm{VO}_{2 \text { peak }}$ and $\mathrm{W}_{\text {peak }}$ in our sample (referred to as calibration-in-the-large). ${ }^{19}$ Third, we calculated and plotted limits of agreement (LOA) of $\mathrm{VO}_{2 \text { peak }}^{\text {pred }}$ and $\mathrm{W}_{\text {peak }}^{\text {pred }}$ with the corresponding values measured during the CPET by using the Bland-Altman method. ${ }^{20}$ The error correlation (expressing the association between the mean of the values and their difference) was calculated and the corresponding regression line added to the Bland-Altman plot.

\section{Model extension}

To extend the 2 regression equations, we conducted multiple linear regression analysis using separate models for $\mathrm{Vo}_{2 \text { peak }}^{\text {cpet }}$ and $\mathrm{W}_{\text {peak }}^{\text {cpet }}$ after visually confirming the linear relations between MSEC and $\mathrm{VO}_{2 \text { peak }}^{\text {cpet }}$ and $\mathrm{W}_{\text {peak }}^{\text {cpet }}$. We started with a full model that included age, height, weight, and sex in addition to MSEC as predictors and used a stepwise backward selection procedure based on the minimization of Akaike's information criterion (an index of goodness of fit) to select sparse models that best predicted $\mathrm{VO}_{2 \text { peak }}^{\text {cpet }}$ and $\mathrm{W}_{\text {peak. }}^{\text {cpet }}{ }^{19,21}$ We repeated the LOA analyses as described above using $\mathrm{Vo}_{2 \text { peak }}^{\text {pred }}$ and $\mathrm{W}_{\text {peak }}^{\text {pred }}$ estimates from the extended multivariable models.

Because estimation of model performance is usually overoptimistic when assessed in the sample in which a model is developed, and regression coefficients are typically too large, we performed internal validation by bootstrapping (100 bootstraps) on the full multivariable model (ie, before stepwise selection). Based on this, uniform shrinkage was applied to the regression coefficients of the reduced model. ${ }^{19}$ The resulting regression equations for $\mathrm{W}_{\text {peak }}^{\text {pred }}$ and $\mathrm{Vo}_{2 \text { peak }}^{\text {pred }}$ are presented as a nomogram.

\section{Clinical performance}

We evaluated the clinical performance of the original and the newly developed prediction model. For $\mathrm{VO}_{2 \text { peak }}$, the percentage of participants whose $\mathrm{Vo}_{2 \text { peak }}$ was misclassified by $>1$ metabolic equivalent (MET) value (taken as $3.5 \mathrm{~mL} \cdot \mathrm{kg}^{-1} \cdot \mathrm{min}^{-1}$ ) was calculated. For $\mathrm{W}_{\text {peak }}$, we evaluated clinical performance on the basis of exercise prescription. A typical exercise prescription at moderate to high intensity would be targeted at $60 \%$ of $\mathrm{W}_{\text {peak }}$. Therefore, we calculated the number of participants for whom an exercise prescription of $60 \% \mathrm{~W}_{\text {peak }}^{\text {pred }}$ fell within \pm 10 percentage point range of the measured $60 \% \mathrm{~W}_{\text {peak }}^{\text {cpet }}$.

\section{Sensitivity analyses}

We performed 2 sensitivity analyses: The first included only patients with a smaller than 7-day interval between the 2 tests to assess the effect of time between tests on the outcome. The second included patients with breast cancer only (the largest uniform subgroup in the sample) to assess the effect of heterogeneity of cancer diagnoses in our sample. All analyses were performed using the statistical software $\mathrm{R}$ version 3.2.1.

\section{Results}

\section{Sample characteristics}

Of the 283 participants, 68 (24\%) were men. The mean age was $53 \pm 11$ years, and the majority $(162,57 \%)$ were breast cancer survivors (table 1).

\section{External validation}

Using the equation for $\mathrm{VO}_{2 \text { peak }}$, as published by De Backer et $\mathrm{al}^{12}$ $(6.7 * \mathrm{MSEC}+356.7)$, the ICC of $\mathrm{Vo}_{2 \text { peak }}^{\text {pred }}$ with $\mathrm{VO}_{2 \text { peak }}^{\text {cpet }} .61$ (95\% confidence interval $[\mathrm{CI}], .41-.74)$. Vo 2 peak showed a bias of $190 \mathrm{~mL} / \mathrm{min}$ as compared with $\mathrm{Vo}_{2 \text { peak }}^{\text {cpet }}$, which likely reflected the lower mean $\mathrm{VO}_{2 \text { peak }}$ in our sample than in the derivation sample $\left(21.7 \mathrm{~mL} \cdot \mathrm{kg}^{-1} \cdot \mathrm{min}^{-1} \quad\right.$ vs $\left.\quad 29.4 \mathrm{~mL} \cdot \mathrm{kg}^{-1} \cdot \mathrm{min}^{-1}\right)$. After calibration-in-the-large, the $5 \%$ LOA were $\pm 705 \mathrm{~mL} / \mathrm{min}$. There was a negative error correlation: $r=-.22$ (fig 1A).

The ICC of $\mathrm{W}_{\text {peak }}^{\text {pred }}$ with $\mathrm{W}_{\text {peak }}^{\text {cpet }}$ was .73 (95\% CI, .67-.78) using the equation for $\mathrm{W}_{\text {peak }}$ as published by De Backer et al (0.65*MSEC-3.88). The Bland-Altman analysis indicated a small bias of $5 \mathrm{~W}$, despite a larger difference in mean $\mathrm{W}_{\text {peak }}$ between our sample and the sample in which the equation was derived (141W vs $183 \mathrm{~W}$ ). After calibration-in-the-large, $95 \%$ LOA were $\pm 59 \mathrm{~W}$, and there was a negative error correlation: $r=-.14$ (fig 1B).

\section{Model extension}

The final multivariable model for the prediction of $\mathrm{VO}_{2 \text { peak }}$ included weight and sex in addition to the MSEC (table 2). The explained variance $\left(R^{2}\right)$ of this model was .58 , and the ICC of $\mathrm{Vo}_{2 \text { peak }}^{\text {pred }}$ with $\mathrm{Vo}_{2 \text { peak }}^{\text {cpet }}$ was $.73(95 \% \mathrm{CI}, .67-.78)$. Using this model for prediction, LOA improved to $\pm 608 \mathrm{~mL} / \mathrm{min}$, but the negative error correlation remained: $r=-.39$ (see fig 1A). After shrinkage, the equation was as follows: $676.8+3.92 * \mathrm{MSEC}+5.02 *$ weight $327.6 *$ female (using 1 for "female" and 0 for "male"). The equation is presented as a nomogram (fig $2 \mathrm{~A}$ ). 
Table 1 Descriptive statistics of the sample $(\mathrm{N}=283)$

\begin{tabular}{|c|c|}
\hline Variable & Value \\
\hline Sex: male & $68(24)$ \\
\hline Age (y) & $53 \pm 11$ \\
\hline Height $(\mathrm{cm})$ & $170 \pm 9$ \\
\hline Body weight (kg) & $77.6 \pm 14.6$ \\
\hline \multicolumn{2}{|l|}{ Cancer type } \\
\hline Breast cancer & $162(57.2)$ \\
\hline Colon cancer & $49(17.3)$ \\
\hline Lymphomas & $56(19.8)$ \\
\hline Ovarian cancer & $8(2.8)$ \\
\hline Cervix cancer & $4(1.4)$ \\
\hline Testis cancer & $4(1.4)$ \\
\hline \multicolumn{2}{|l|}{ Treatment } \\
\hline Chemotherapy & $283(100)$ \\
\hline Radiotherapy & $123(43)$ \\
\hline Surgery & $227(80)$ \\
\hline Stem cell transplantation & $32(11)$ \\
\hline Immunotherapy & $51(18)$ \\
\hline Hormone therapy & $114(40)$ \\
\hline Weeks since treatment & $8 \pm 3.7$ \\
\hline $\mathrm{V}_{0_{2 \text { peak }}}(\mathrm{mL} / \mathrm{min})$ & $1713.7 \pm 476.0$ \\
\hline $\mathrm{V}_{0_{2 \text { peak }}}\left(\mathrm{mL} \cdot \mathrm{kg}^{-1} \cdot \mathrm{min}^{-1}\right)$ & $21.7 \pm 5.7$ \\
\hline$W_{\text {peak }}(W)$ & $141 \pm 43.1$ \\
\hline MSEC (W) & $231 \pm 60.4$ \\
\hline
\end{tabular}

NOTE. Values are mean \pm SD or $n(\%)$.

For $\mathrm{W}_{\text {peak }}$, the final model included height, sex, and age in addition to the MSEC (see table 2). The $R^{2}$ of this model was .67 . The ICC of $\mathrm{W}_{\text {peak }}^{\text {pred }}$ with $\mathrm{W}_{\text {peak }}^{\text {cpet }}$ was $.81(95 \% \mathrm{CI}, .76-.84)$. Compared to the original equation, LOA improved to $\pm 48 \mathrm{~W}$, but the error correlation was larger: $r=-.33$ (see fig 1B). After shrinkage of the coefficients, the equation was $0.33 *$ MSEC $+124 *$ height $(\mathrm{m})-22.4 *$ female $-0.47 *$ age -107 . This equation is also presented as a nomogram (fig $2 \mathrm{~B}$ ).

\section{Clinical performance}

Using the original equation, $56 \%$ of the patients were misclassified by $>1 \mathrm{MET}$. An exercise prescription aimed at achieving

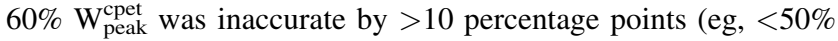
or $>70 \%$ of $\mathrm{W}_{\text {peak }}^{\text {cpet }}$ ) in $43 \%$ of the sample. After calibration-in-thelarge, this reduced to $44 \%$ and $39 \%$ of the patients, respectively. Using the reestimated, multivariable prediction models, the percentage further reduced to $36 \%$ and $32 \%$, respectively.

\section{Sensitivity analyses}

No significant and meaningful differences in the LOA or clinical applicability were observed when restricting the sample to patients with a measurement interval $<7$ days $(n=109)$ or breast cancer survivors only $(n=139)$.

\section{Discussion}

This study examined the validity and clinical applicability of regression-based estimates of $\mathrm{VO}_{2 \text { peak }}$ and $\mathrm{W}_{\text {peak }}$ in cancer survivors by using the SRT. In particular, we evaluated the external validity of previously derived prediction models for this population and aimed to improve predictions by extending the regression models.

Our results confirm the linear relations of MSEC with $\mathrm{VO}_{2}^{\text {peak }}$ and $\mathrm{W}_{\text {peak }}$ that were also described in previous studies of cancer survivors, patients with type 2 diabetes mellitus, and healthy children and adolescents. ${ }^{12,13,22}$ As far as we know, no validation studies have been conducted to externally validate the prediction rules derived in these studies.

The bias observed in the LOA analysis shows that the accuracy of the predicted values $\mathrm{VO}_{2 \text { peak }}^{\text {pred }}$ and $\mathrm{W}_{\text {peak }}^{\text {pred }}$ is affected if the mean values of $\mathrm{VO}_{2 \text { peak }}^{\text {cpet }}$ and $\mathrm{W}_{\text {peak }}^{\text {cpet }}$ in the target population are different from those of the population in which the equation was derived (miscalibration in the large). Although predictions improved by extending the regression models, they are still suboptimal. The agreement between the values as predicted by the extended models and the actual values could be considered sufficiently high at the group level. However, higher agreement (ICCs, >0.9) is usually considered preferable for decision making at the individual level. ${ }^{23}$ Also, the LOA, which have a stronger influence on clinical usability than the ICCs, are still wide. This is illustrated by the high percentage of patients that were misclassified by $>1 \mathrm{MET}$ in the present study.
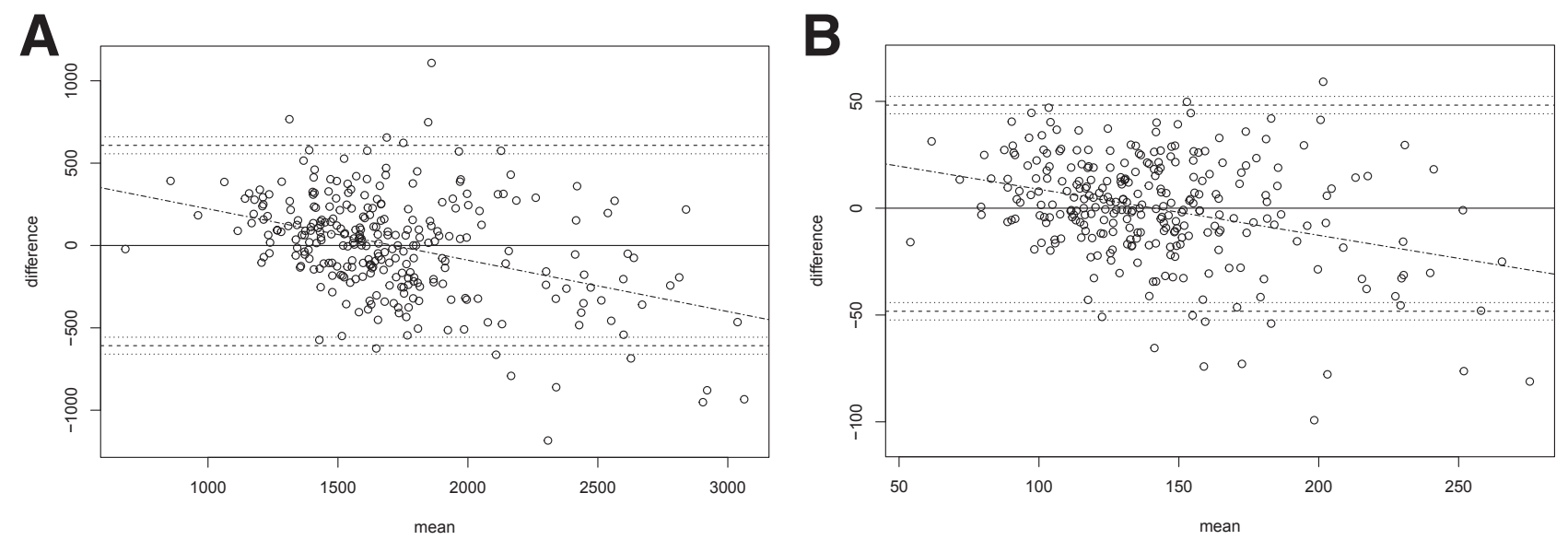

Fig 1 Bland-Altman plots for the estimation of $\mathrm{V}_{0_{2 p e a k}}(\mathrm{~A})$ and $\mathrm{W}_{\text {peak }}(\mathrm{B})$ after reestimation and extension of the prediction model. Dashed lines indicate $95 \%$ LOA; dotted lines indicate $95 \%$ confidence interval of the limits, and the diagonal line indicates linear regression fit of difference vs mean. 
Table 2 Regression coefficients for multivariable linear regression model predicting $\mathrm{V}_{0}$ peak and $\mathrm{W}_{\text {peak }}$ using the SRT

\begin{tabular}{lccc}
\hline & \multicolumn{3}{c}{$95 \%$ Confidence } \\
Variable & $\beta$ & Interval for $\beta$ & $\beta$ After Shrinkage \\
\hline$V_{0_{\text {2peak }}}$ & & & \\
$\quad$ MSEC & 3.97 & 3.29 to 4.65 & 3.92 \\
$\quad$ Body weight & 5.09 & 2.37 to 7.80 & 5.02 \\
Sex: female & -332 & -432 to -232 & -328 \\
W $_{\text {peak }}$ & & & \\
$\quad$ MSEC & 0.34 & 0.28 to 0.40 & 0.33 \\
Age & -0.47 & -0.75 to -0.19 & -0.47 \\
Height & 126 & 82.1 to 169 & 124 \\
Sex: female & -22.6 & -31.9 to -13.3 & -22.4 \\
\hline
\end{tabular}

In addition to quantification of peak exercise capacity, identification of the limiting system (cardiovascular, pulmonary, musculoskeletal, psychological) and assessment of exerciseinduced cardiovascular risks can be of relevance in the context of cancer rehabilitation. Such information cannot be obtained using the SRT. Also, without measuring gas exchange, it can be difficult to ascertain peak performance. Therefore, despite its advantage of being quick and easily applicable, the SRT should not be considered an alternative to a CPET when a valid measurement of $\mathrm{VO}_{2 \text { peak }}$ is needed for an individual patient or when the exercise capacity limiting system needs to be identified for clinical decision making.

As expected, the clinical applicability of the original prediction model for the estimation of $\mathrm{W}_{\text {peak }}$ in cancer survivors was also insufficient for accurate aerobic exercise prescription (based on a constant percentage of estimated $\mathrm{W}_{\text {peak }}$ ) in our sample. This could be improved considerably by calibration-in-the-large and even further after extending the equation with height, age, and sex. Nevertheless, clinicians should be aware of the possibility of overor underestimation of exercise capacity when using $\mathrm{W}_{\text {peak }}^{\text {pred }}$ for individual exercise prescription. The observed negative error correlation implies an overestimation of $\mathrm{Vo}_{2 \text { peak }}$ and $\mathrm{W}_{\text {peak }}$ in cancer survivors with lower cardiorespiratory fitness and underestimation in those with high cardiorespiratory fitness. The presented nomogram (see fig 2) is expected to have sufficient accuracy in about two thirds of cancer survivors.

One could argue on the basis of our results that CPET remains a preferred choice for exercise prescription. However, several studies have shown that even with available CPET data, accurate exercise prescription for cancer survivors, for example, based on the percentage of maximum heart rate, can be challenging because of changes in exercise response. ${ }^{24-26}$ Also, repeated testing is required to ensure sufficient overload during the course of the exercise program, and repeated CPETs are difficult to implement in regular care. In a recent study, repeated SRTs was used in combination with Borg scores of perceived exertion to prescribe fixed load endurance exercise during chemotherapy. Patients after this program successfully maintained physical fitness throughout chemotherapy. ${ }^{27}$ Clearly, more studies are needed to examine the accuracy of different ways to tailor exercise prescription, and the role of different exercise tests, in cancer survivors.

\section{Study strengths}

Strengths of this study include the relatively large sample that allowed for a robust analysis strategy, including sensitivity analyses by test interval and tumor type, and the use of a heterogeneous sample of cancer survivors. Although it is likely that the performance of the extended prediction models will be somewhat less when applied to other patients, our results are expected to translate reasonably to clinical practice because shrinkage was applied to the regression coefficients. ${ }^{19,21}$

\section{Study limitations}

This study also had some limitations that should be noted. We used data that were gathered in the context of randomized controlled trials evaluating the effects of exercise interventions in cancer survivors. ${ }^{15,17}$ The timing of the tests relative to each other was not fixed, but depended on trial logistics. We tried to limit the potential effect of time between measurements by selecting only those cancer survivors who were tested on the CPET and SRT within a maximum range of 30 days. Because the sensitivity analysis in survivors with a maximum time interval between the tests of 7 days showed comparable results, we believe that the
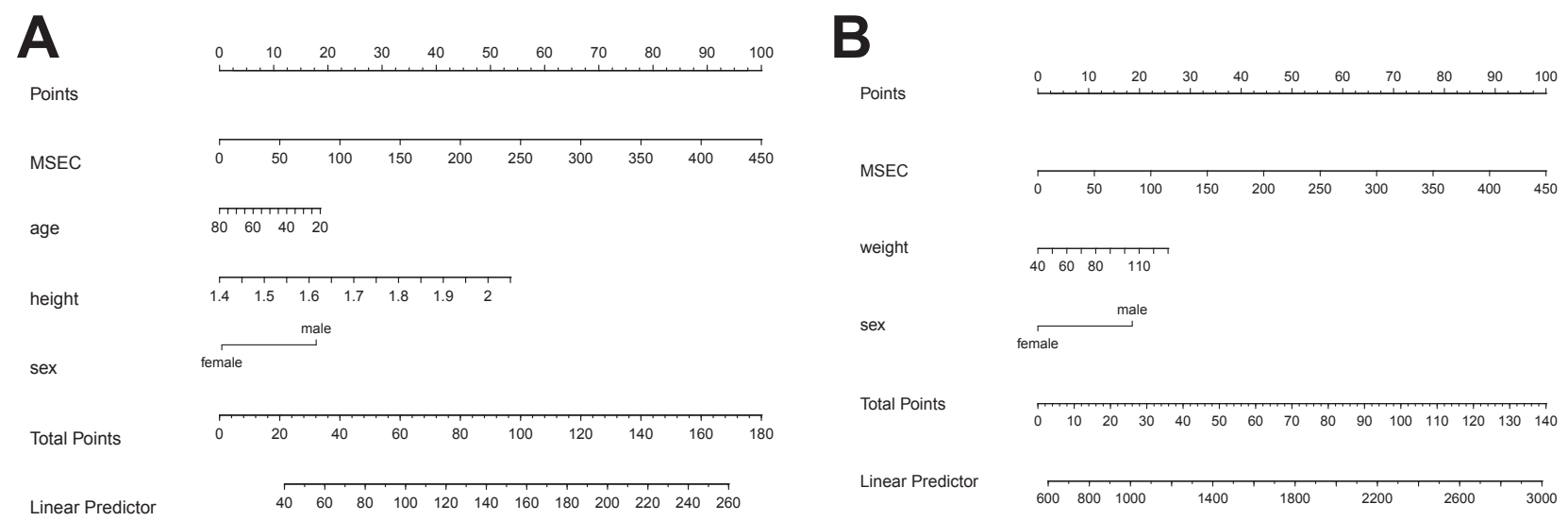

Fig 2 Nomograms for the prediction of $\mathrm{W}_{\text {peak }}(\mathrm{A})$ and $\mathrm{V}_{0_{2 p e a k}}(\mathrm{~B})$. The value of each variable corresponds to a number of points on the top scale. Points are summed. The total points can then be used to read the linear predictor (estimated $W_{\text {peak }}$ or $V_{0_{2 p e a k}}$ ) from the bottom scale. For example, for a patient who achieves an MSEC of 250W (56 points), weighs $86 \mathrm{~kg}$ (13 points), and is a female (0 points), the total points are 69 , which corresponds to a linear predictor of $\sim 1760 \mathrm{~mL} / \mathrm{min}$. 
timing had limited effect on our findings. Second, although the exercise tests were carried out according to standardized protocols, the SRT measurements were conducted by different physical therapists offering the exercise programs. This may have introduced random error in the measurements, reducing the observed validity of the SRT, but it does resemble the way the SRT will be used in clinical practice.

The sample was limited to cancer survivors who had recently completed treatment. It is unclear whether the results are generalizable to cancer survivors during active treatment. Factors such as fatigue, anxiety, nausea, or lack of motivation may be more prominent during active treatment, and may affect the workload achieved on the SRT more profoundly than that on the CPET, because of the short duration and steep increments used in the SRT. It is conceivable that this will influence the relation of the MSEC with $\mathrm{VO}_{2 \text { peak }}$ and $\mathrm{W}_{\text {peak }}$. Future research should further explore these issues.

For cancer survivors who completed treatment, the presented nomogram provides added value to support personalized endurance exercise intensity prescription based on the SRT. However, the nomogram-predicted values should be considered a starting point and further adaptation (eg, using Borg scores) may still be necessary for individual patients.

\section{Conclusions}

The results of this study suggest that although predictions of $\mathrm{VO}_{\text {2peak }}$ and $\mathrm{W}_{\text {peak }}$ based on the SRT could be considered acceptable at the group level, they do not provide sufficiently accurate estimations of endurance exercise capacity in individual cancer survivors. Nevertheless, the prediction of $\mathrm{W}_{\text {peak }}$ using the presented multivariable prediction rule or the associated nomogram can be used cautiously (eg, supplemented with a Borg score) to aid endurance exercise prescription in this population.

\section{Supplier}

a. $\mathrm{R}$ version 3.2.1; R Foundation for Statistical Computing.

\section{Keywords}

Exercise test; Exercise therapy; Neoplasms; Rehabilitation; Validation studies

\section{Corresponding author}

Martijn M. Stuiver, PhD, The Netherlands Cancer Institute-Antoni van Leeuwenhoek Hospital, Physiotherapy, Plesmanlaan 121, Amsterdam 1066CX, The Netherlands. E-mail address: m.stuiver@nki.nl.

\section{Acknowledgments}

We thank the Alpe d'HuZes Cancer Rehabilitation Clinical Research Group and all the patients, oncologists, nurses, physical therapists, and scientific staff who participated in the trials.

\section{References}

1. Vermaete N, Wolter P, Verhoef G, Gosselink R. Physical activity and physical fitness in lymphoma patients before, during, and after chemotherapy: a prospective longitudinal study. Ann Hematol 2014; 93:411-24.

2. Steins B, Velthuis MJ, Wittink H. Cardiopulmonary exercise testing in cancer rehabilitation: a systematic review. Sports Med 2012;42:36779.

3. Ainsworth BE, Haskell WL, Herrmann SD, et al. 2011 Compendium of Physical Activities: a second update of codes and MET values. Med Sci Sports Exerc 2011;43:1575-81.

4. Jones LW, Courneya KS, Mackey JR, et al. Cardiopulmonary function and age-related decline across the breast cancer survivorship continuum. J Clin Oncol 2012;30:2530-7.

5. Jones LW, Watson D, Herndon JE II, et al. Peak oxygen consumption and long-term all-cause mortality in nonsmall cell lung cancer. Cancer 2010;116:4825-32.

6. Schmid D, Leitzmann MF. Cardiorespiratory fitness as predictor of cancer mortality: a systematic review and meta-analysis. Ann Oncol 2015;26:272-8

7. Schmitz KH, Courneya KS, Matthews C, et al; American College of Sports Medicine. American College of Sports Medicine roundtable on exercise guidelines for cancer survivors. Med Sci Sports Exerc 2010; 42:1409-26.

8. Winters-Stone KM, Neil SE, Campbell KL. Attention to principles of exercise training: a review of exercise studies for survivors of cancers other than breast. Br J Sports Med 2014;48:987-95.

9. Campbell KL, Neil SE, Winters-Stone KM. Review of exercise studies in breast cancer survivors: attention to principles of exercise training. Br J Sports Med 2012;46:909-16.

10. Jones LW, Eves ND, Haykowsky M, Joy AA, Douglas PS. Cardiorespiratory exercise testing in clinical oncology research: systematic review and practice recommendations. Lancet Oncol 2008;9:757-65.

11. Meyer K, Samek L, Schwaibold M, et al. Interval training in patients with severe chronic heart failure: analysis and recommendations for exercise procedures. Med Sci Sports Exerc 1997;29:306-12.

12. De Backer IC, Schep G, Hoogeveen A, Vreugdenhil G, Kester AD, van Breda E. Exercise testing and training in a cancer rehabilitation program: the advantage of the steep ramp test. Arch Phys Med Rehabil 2007;88:610-6.

13. Bongers BC, De Vries SI, Helders PJ, Takken T. The steep ramp test in healthy children and adolescents: reliability and validity. Med Sci Sports Exerc 2013;45:366-71.

14. Jurca R, Jackson AS, LaMonte MJ, et al. Assessing cardiorespiratory fitness without performing exercise testing. Am J Prev Med 2005;29: 185-93.

15. Persoon S, Kersten MJ, Chinapaw MJ, et al. Design of the EXercise Intervention after Stem cell Transplantation (EXIST) study: a randomized controlled trial to evaluate the effectiveness and costeffectiveness of an individualized high intensity physical exercise program on fitness and fatigue in patients with multiple myeloma or (non-) Hodgkin's lymphoma treated with high dose chemotherapy and autologous stem cell transplantation. BMC Cancer 2010;10:671.

16. Kampshoff CS, Buffart LM, Schep G, van Mechelen W, Brug J, Chinapaw MJ. Design of the Resistance and Endurance exercise After ChemoTherapy (REACT) study: a randomized controlled trial to evaluate the effectiveness and cost-effectiveness of exercise interventions after chemotherapy on physical fitness and fatigue. BMC Cancer 2010;10:658.

17. Kampshoff CS, Chinapaw MJ, Brug J, et al. Randomized controlled trial of the effects of high intensity and low-to-moderate intensity exercise on physical fitness and fatigue in cancer survivors: results of the Resistance and Endurance exercise After ChemoTherapy (REACT) study. BMC Med 2015;13:275. 
18. Chinapaw MJ, Buffart LM, van Mechelen W, et al. Alpe d'HuZes Cancer Rehabilitation (A-CaRe) research: four randomized controlled exercise trials and economic evaluations in cancer patients and survivors. Int J Behav Med 2011;19:143-56.

19. Steyerberg E. Clinical prediction models. New York: Springer; 2008.

20. Bland JM, Altman DG. Statistical methods for assessing agreement between two methods of clinical measurement. Lancet 1986;1:307-10.

21. Harrell F. Regression modeling strategies. Cham, Switzerland: Springer; 2015.

22. Rozenberg R, Bussmann JB, Lesaffre E, Stam HJ, Praet SF. A steep ramp test is valid for estimating maximal power and oxygen uptake during a standard ramp test in type 2 diabetes. Scand J Med Sci Sports 2015;25:595-602.

23. Nunnally JC, Bernstein IH. Psychometric theory. 3rd ed. Delhi, India: Tata McGraw-Hill Education; 2010.
24. Scharhag-Rosenberger F, Kuehl R, Klassen O, et al. Exercise training intensity prescription in breast cancer survivors: validity of current practice and specific recommendations. J Cancer Surviv 2015;9:612-9.

25. Kirkham AA, Campbell KL, McKenzie DC. Comparison of aerobic exercise intensity prescription methods in breast cancer. Med Sci Sports Exerc 2013;45:1443-50.

26. Kuehl R, Scharhag-Rosenberger F, Schommer K, et al. Exercise intensity classification in cancer patients undergoing allogeneic HCT. Med Sci Sports Exerc 2015;47:889-95.

27. van Waart H, Stuiver MM, van Harten WH, et al. Effect of lowintensity physical activity and moderate- to high-intensity physical exercise during adjuvant chemotherapy on physical fitness, fatigue, and chemotherapy completion rates: results of the PACES randomized clinical trial. J Clin Oncol 2015;33: 1918-27. 